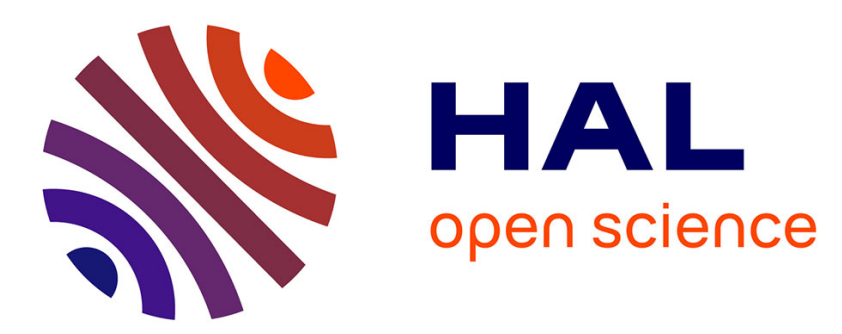

\title{
Radiation Effects in Thin-Film Ferroelectric PZT for Non-Volatile Memory Applications in Microelectronics
}

Jean-Luc Leray, Olivier Musseau, Philippe Paillet, Jean-Luc Autran, Frédéric Sodi, Yves-Marie Coïc

\section{- To cite this version:}

Jean-Luc Leray, Olivier Musseau, Philippe Paillet, Jean-Luc Autran, Frédéric Sodi, et al.. Radiation Effects in Thin-Film Ferroelectric PZT for Non-Volatile Memory Applications in Microelectronics. Journal de Physique III, 1997, 7 (6), pp.1227-1243. 10.1051/jp3:1997185 • jpa-00249644

\section{HAL Id: jpa-00249644 https://hal.science/jpa-00249644}

Submitted on 1 Jan 1997

HAL is a multi-disciplinary open access archive for the deposit and dissemination of scientific research documents, whether they are published or not. The documents may come from teaching and research institutions in France or abroad, or from public or private research centers.
L'archive ouverte pluridisciplinaire HAL, est destinée au dépôt et à la diffusion de documents scientifiques de niveau recherche, publiés ou non, émanant des établissements d'enseignement et de recherche français ou étrangers, des laboratoires publics ou privés. 


\title{
Radiation Effects in Thin-Film Ferroelectric PZT for Non-Volatile Memory Applications in Microelectronics
}

\author{
Jean-Luc Leray $\left({ }^{*}\right)$, Olivier Musseau, Philippe Paillet, Jean-Luc Autran, \\ Frédéric Sodi and Yves-Marie Coïc \\ Commissariat à l'Énergie Atomique, Centre d'Études de Bruyères-Le-Châtel, B P 12, \\ 91680 Bruyères-Le-Châtel, France
}

(Received 11 June 1996, revised 10 February 1997, accepted 11 February 1997)

PACS 77.80 -e - Ferroelectricity and antiferroelectricity
PACS.77.84 -s - Dielectric, piezoelectric and ferroelectric materials
PACS.85.50.+k - Dielectric, ferroelectric and piezoelectric devices

\begin{abstract}
This paper deals with ionising radiation effects (X or $\gamma$-rays) in ferroelectric materials for electronic non-volatile memories. After the recall of main observations, mechanisms are analysed and proposed to take into account the effects in PZT-based capacitors. Fatigue of the hysteresis cycle are studied and linked to irradiation effects. As for irradiation, fatigue shows a damping of hysteresis curves. We show that a connection exists between fatigue and irradiation. A mechanism is proposed based on domain wall motion and pinning.
\end{abstract}

Résumé. - Cet article traite des effets des radiations ionisantes (rayons $\mathrm{X}$ ou $\gamma$ ) dans les matériaux ferroélectriques destinés aux composants électronıques utılısant des couches minces polarisables (mémoires non-volatiles) Après avoir rappelé les types d'observations, on propose certains mécanismes pour décrire ces effets dans les capacités à base de PZT Les effets de fatigue du cycle d'hystérésis sont étudiés et interprétés en les couplant aux effets d'une irradiation. Comme l'ırradiation, la fatigue par cyclage montre un aplatissement des courbes d'hystérésis Dans cet exposé, on montre qu'il existe un parallèle entre les effets des irradiations et de la fatigue. Un mécanisme est proposé basé sur le mouvement des parois de domaine et son empêchement progressif par épinglage des parois.

\section{Introduction}

1.1. Radiation Environments for Electronic Components. - The necessity of electronic components resistzng to ionising radiations concerns various applications. It concerns a field vast enough, such as satellites that orbit in Van Allen belts, equipments of the nuclear energy industry (reactors, waste containers and hot cells for reprocessing of used fuels), and also particles detectors placed in the vicinity of the great accelerators. In particular, one special component is commonly used in any of these equipments, namely the memory.

Along their tracks, all the ionizing particles generate electrons and holes. For the muons commonly encountered at ground level as by-products of the interaction of cosmic rays with

$\left(^{*}\right)$ Author for correspondence (e-mail: leray@bruyeres.cea.fr)

(C) Les Éditions de Physique 1997 
atmosphere (about one particle per $\mathrm{cm}^{2}$ per hour), 1 to $10 \mathrm{fC}$ are generated per micron in semiconductors, depending on the density and band-gap energy of the material. In space, protons or heavy ion cosmic rays can directly generate much more, from $10 \mathrm{fC} \mu \mathrm{m}^{-1}$ to $1 \mathrm{pC} \mu \mathrm{m}^{-1}$. As detailed elsewhere [1], this ionization phenomenon leads to the buildup of a trapped charge in insulators and of interface traps at the semiconductor-insulator interface (permanent effects) as well as the production of photocurrents in semiconductor junctions (transient effects). These perturbations of charges or currents cause the memory to loss the stored information. The currently available devices have radiation tolerance inferior by several orders of magnitude ( 2 to 3 ) to what it is desirable. Ferroelectric capacitors have been proposed as a sure and elegant solution to solve problems of information stocked in such memories.

1.2. Ferroelectric Memories. - The ferroelectric non-volatile memory (FERAM) concept consists of a standard electric circuit technology (commonly CMOS although GaAs has been cited) and $a d d$-on specific layers of ferroelectric capacitor in which the polarization dipoles are remanently oriented during the storage operation of the memory. The ferroelectric capacitors consist of thin layers sandwiched between metal electrodes (typical structures of 0.2 to $0.5 \mu \mathrm{m}$ are described in Annex B).

1.3. Radiation Effects in Thick Ferroelectric Crystals and Ceramics. - The effects of radiations in bulk ferroelectric materials have been studied since the 1950s [2-5]. Various effects have been listed, for instance in the case of $\mathrm{BaTiO}_{3}$ : (i) $13 \%$ decline of the coercive field at $3 \times 10^{15}$ neutrons $\mathrm{cm}^{-2}$ (ii) phase transition forced at room temperature when exposed to very high fluences of $10^{20}$ neutrons $\mathrm{cm}^{-2}[3,4]$. For the exposure to gamma rays the coercive field in $\mathrm{BaTiO}_{3}$ decreased $25 \%$ at 100 megaröntgens [4], which is a very promising result.

Other interesting pioneering works were reported by [2] and [5], which concerned slices of cleaved triglycine sulfate (125 $\mu \mathrm{m}$ thick). The irradiation with $30 \mathrm{keV} \mathrm{X}$-rays first evidenced the "poling effect". In single crystals, hysteresis loop was deformed as pictured in Figure 1 left (a), in which the direction of the electric field axis shift is related to the direction of the polarization during the irradiation time. The direction of the shift is positive if the crystal was polarized in the state $-P_{\mathrm{r}}$ during irradiation, as pictured in Figure 1. In multidomain crystals, of triglycine sulfate, the situation is pictured in Figure 1 right (b), where loops appear and drift further apart and the capacitor degrade more [5].

The author concluded that the clean separation of the loops showed that the effects in part of the crystal polarized in a given direction proceeded independently from the effect in region polarized in the opposite direction. These observations in thick slices guided the work on thin films exposed hereafter.

1.4. Radiation Effects in Ferroelectric Thin Films. - In thin layer of ceramic materials exposed to irradiations, few data have been published until this day [6-8]. This paper brings updated data concerning $\mathrm{PbZr}_{1-x} \mathrm{Ti}_{x} \mathrm{O}_{3}(x=80 \%)$, obtained by the sol-gel method. These samples (thickness of $0.3 \mu \mathrm{m}$ with platinum electrodes) have been prepared by the company "Radiant" (see [25]).

General observatzons (Fig. 2). - Hysteresis loops keep the same kind of shape. The diminution of $P_{\mathrm{r}}$ is well observed. The value of the shift is in the order of 1 to 2 volts at 100 megarad(Si), and does not depend on dimensions of the sample. A straightforward interpretation consists in supposing an internal field superposed to the applied field. The corresponding value would be approximately 35 to $70 \mathrm{kV} \mathrm{cm}{ }^{-1}$. Furthermore, under this hypothesis, an estimation of the number of trapped charges induced by the irradiation could be made from $\Delta Q=C \Delta V^{r}$ or 


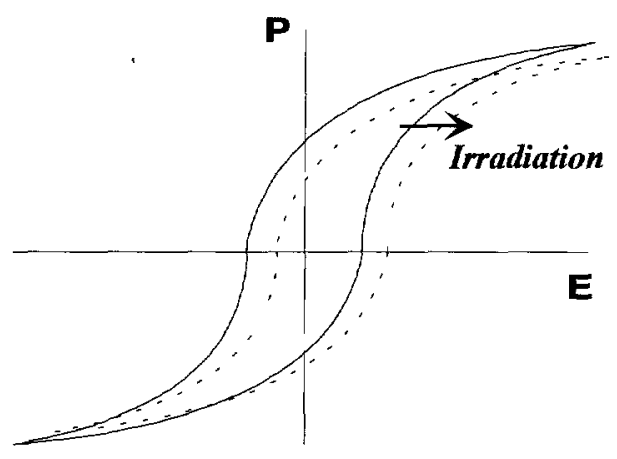

(a)

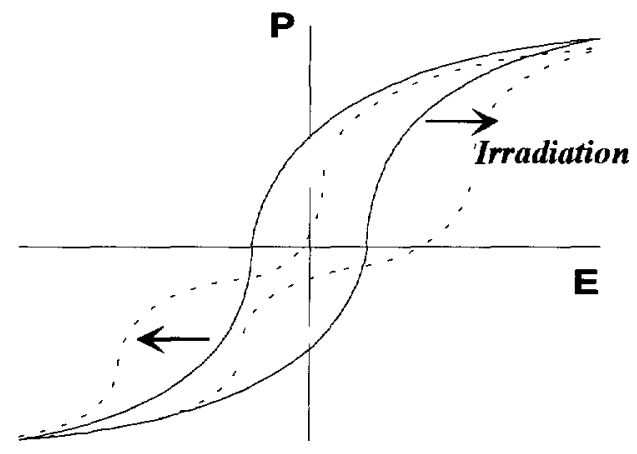

(b)

Fig 1. - Observations in bulk ferroelectric materials: hysteresis loop in single (a) or multiple (b) ferroelectric domains in triglicyne sulfate before (thin line) and after $30 \mathrm{keV}$ X-rays irradiation (dotted line) (after [5]).

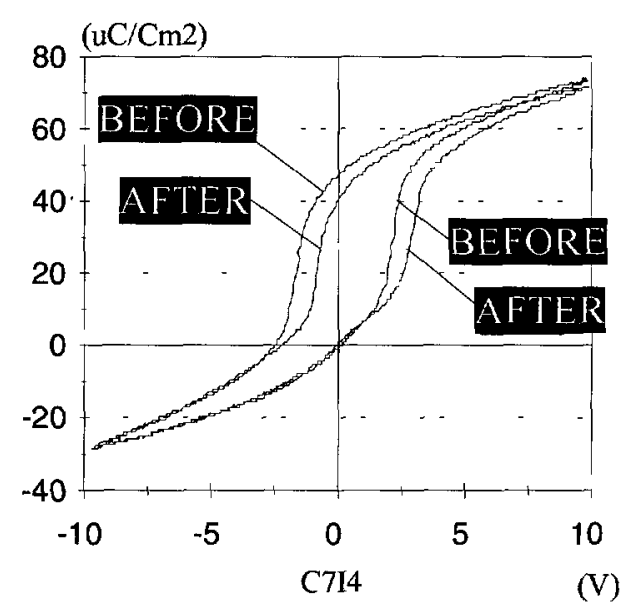

Fig 2. - Hysteresis loop before and after an X-ray irradiatıon of 100 megarads $\left(12 \times 12 \mu \mathrm{m}^{2}\right.$ capacitor).

$\Delta D=\epsilon_{\mathrm{r}} \epsilon_{0} \Delta E$. With $\epsilon_{\mathrm{r}} \cong 1500$ (to the maximum), such a field would correspond to a layer

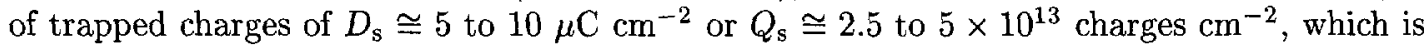
a very large value. A more refined estimation could be made by using the differential value of the dielectric constant, by integrating $\epsilon(E)$ between zero-field to the measurement values. The result of the new estimate is in the order of $10^{12}$ to $10^{13}$ charges $\mathrm{cm}^{-2}$.

\section{An Analysis of Degradation Mechanisms Due to the Irradiation}

Generation of charges. - Ferroelectric ceramic materials present forbidden bandgaps of 3 to $5 \mathrm{eV}$ (approximately $3.5 \mathrm{eV}$ for PZT) and are normally considered as insulating. The irradiation creates electron-hole pairs which undergo the influence of the field existing in the 
different domains. One can estimate the value of this internal average field (Maxwell field):

$$
E_{\mathrm{M}}=\frac{E_{\mathrm{ext}}}{\epsilon_{\mathrm{r}}}=\frac{P}{\epsilon_{0} \chi} .
$$

But, to the microscopic level, the local field $E_{\mathrm{L}}$ is much higher, even in the volume of a domain (Lorentz field):

$$
E_{\mathrm{L}}=\frac{P}{3 \epsilon_{0}}
$$

The location of trapped charges. - Even in the absence of applied external field, a strong local field exists (for $P_{\mathrm{r}}=50 \mu \mathrm{C} \mathrm{cm} \mathrm{cm}^{-2}, E_{\mathrm{L}}=2 \times 10^{8} \mathrm{~V} \mathrm{~cm}^{-1}$ ). It ensures that electrons and holes created by irradiation are violently separated and are then trapped on impurities (and modify their charge state, as it has been demonstrated by the measure of the spin resonance of irradiated materials [9]). Other location of trapping can be lattice point defects, stoichiometric defects, and grain boundaries [10]. As PZT is polycrystalline, a lot of traps are situated on the surface of monocrystalline grains. The trapped charges create electrostatic boundary conditions that prevent ferroelectric domains to propagate and that can fraction them. This causes the diminution of the remanent polarization $P_{\mathrm{r}}$.

Materials with small grains present therefore a larger number of traps by capacitor surface unit [6]. This could explain differences between experiments made on sample from different origins.

2.1. Surface or Perimetric EFfect? - For integrated ferroelectric capacitors of type "thin layer", the aspect ratio between dimension of the surface of the electrode and the lateral surface, related to the thickness and perimeter, is large. It follows that the number of grains is supposed to be small in the axis of thickness, while the volume of the capacitor is composed of a large number of parallel domains and grains. It is therefore interesting to obtain data pertaining to the effect of the aspect ratio of lateral dimension/thickness. For that purpose, a series of capacitors has been used with different perimeter/surface ratios.

Results are exposed in Figure 3. No effect of permeter/surface ratio is visıble, indicating that the material is homogeneous. Grains and ferroelectric domains are probably distributed uniformly and most of the effects concern the volume of the ferroelectric rather than the perimeter boundary.

2.2. Effect of Applied Voltage Bias Conditions During the Irradiation. - In this study, two conditions were used: either the capacitors were biased by a polarization of 5 volts exceeding the coercive tension, so that the orientation of dipoles is forced during the irradiation, or the capacitors were left in the pre-irradiation state by applying only a zero voltage.

Figure 4 it is clearly seen that forced polarization (well beyond the coercive voltage result in weaker degradation. Figure 5 is reported the shift observed asymmetrically according to the polarization bias.

This type of behaviour has been observed previously in this range of dose [11]. A shift along the axis of tensions is observed as predicted by the rule "the direction of shift is equivalent to an applied bias favouring the state of polarization initially existing in the material before the irradiation" [12].

Under zero external voltage, as a consequence of equation (1), the mean internal field $E_{\mathrm{M}}$ determines the curve shift. For applied voltage exceeding coercive value, the differential dielectric constant $\epsilon(E)$ drops and the external field penetrates in the ferroelectric domains. In this case, the external field is the driving force for charges motion. One can thus explain the "poling" 


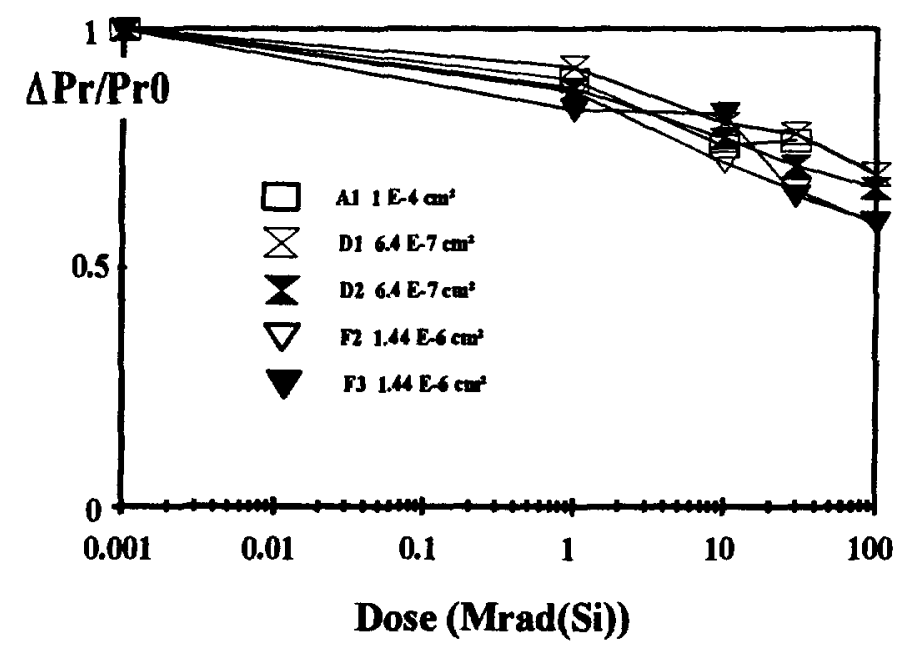

Fig 3. - Variations of the polarization according to the dose for X-ray irradiation (applied voltage was zero during the irradiation).

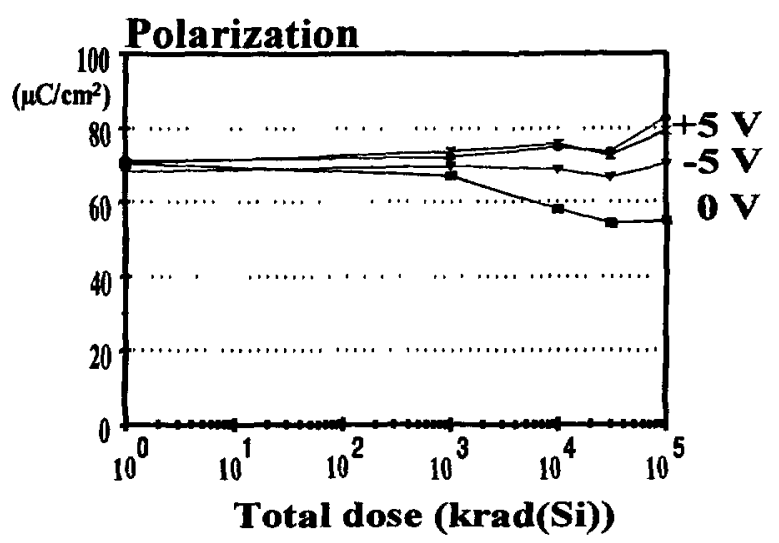

Fig. 4. - The polarization $P_{\mathrm{r}}$ versus the irradiation dose for three cases of external bias $\left(12 \times 12 \mu \mathrm{m}^{2}\right.$ capacitor).

effect as caused by the equivalence of the internal polarization with an external polarization (bias), provided critical coercive values are not exceeded.

2.3. Effect of Isochronal Anneals on the Polarization $P_{\mathbf{R}}$ - - The "isochronal annealing" technique consists in gradually heating the irradiated samples to enhance the rate of different processes: electrical (detrapping, movements of charge) or chemical (change of oxidation state, redistribution of ions, out-diffusion). The capacitors were irradiated beforehand at room temperature (100 megarads under zero applied voltage). Then, the isochronal annealing sequence took place: (1) introduction in the oven placed at a given temperature, (2) anneal during 10 minutes, (3) out-pulling of the sample and measurement at the room temperature, (4) increase of the temperature by a defined step and reiteration of the sequence. 


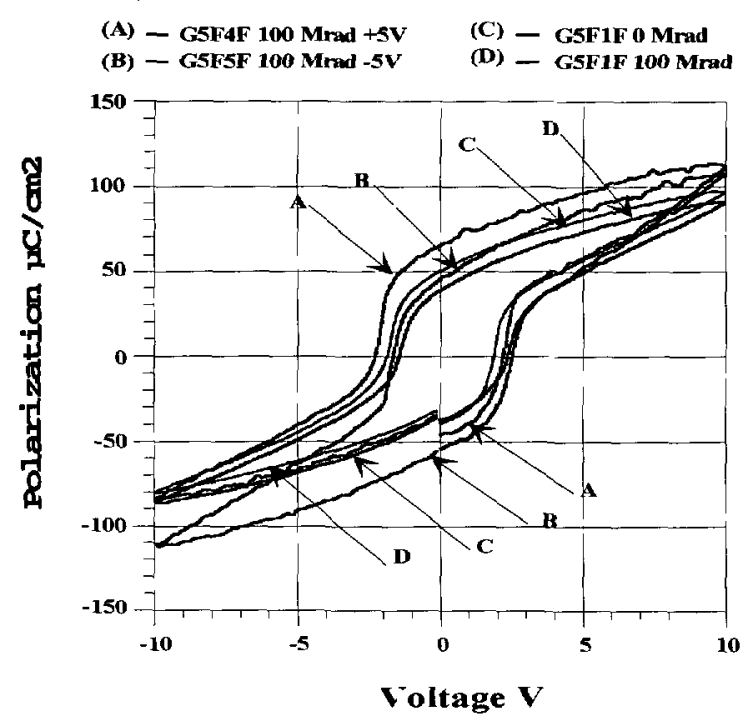

Fig. 5. - Hysteresis curves before and after an $\mathrm{X}$ irradiation of $100 \mathrm{megarad}(\mathrm{Si})$ for a $12 \times 12 \mu \mathrm{m}^{2}$ capacitor) Different voltages have been applied during the irradiation.

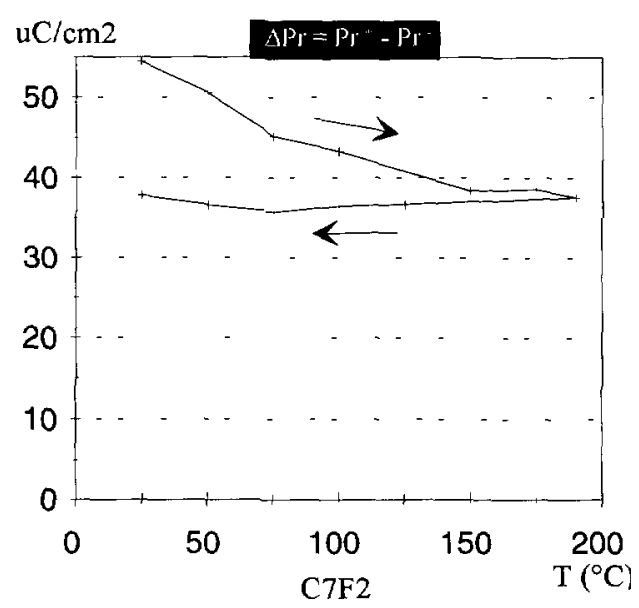

Fig. 6. - Isochronal annealing anneals curves of the parameter $\Delta P_{\mathrm{r}}=P_{\mathrm{r}}^{+}-P_{\mathrm{r}}^{-}$versus temperature raise and descent.

Effect on the polarization. - Figure 6 shows that the polarization decreased as the temperature of the isochronal anneal increased. This graph also shows the return curve, obtained by continuation of the isochronal annealing in a decreasing range of temperatures.

The "return" curve is flat, which demonstrate that the phenomenon of degradation is irreversible. One can therefore deduce that it concerns phenomenon such as migration of charge or chemical defects.

Effect on the coercive field. - The same technique of annealing is applied on the study of coercive voltages $V_{\mathrm{c}^{+}}, V_{\mathrm{c}^{-}}$, and the central value $1 / 2\left(V_{\mathrm{c}}^{+}+V_{\mathrm{c}}^{-}\right)$. One can see (Fig. 7$)$ the initial dissymmetry after irradiation, $V_{\mathrm{c}^{+}}=2.8 \mathrm{~V} ; V_{\mathrm{c}^{-}}=-0.6 \mathrm{~V}$, which results, as exposed 


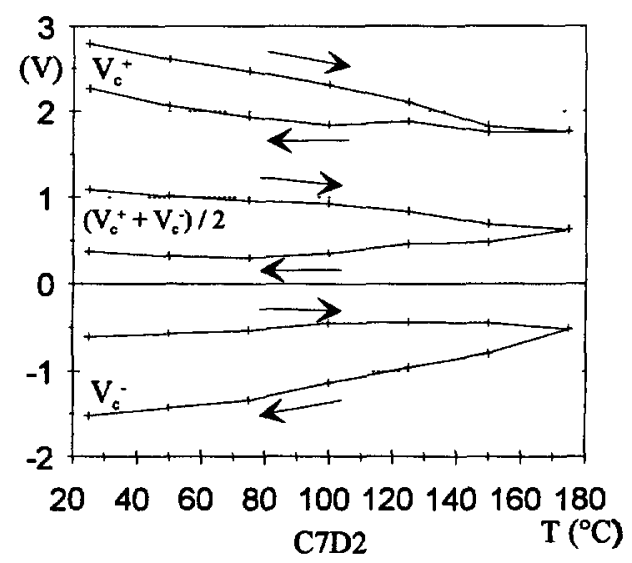

Fig 7. - Isochronal annealing anneals. curves of three parameters associated to the coercive fields versus temperature raise and descent.

previously, from the "poling" effect due to the internal polarization state during the irradiation, which directs charges asymmetrically to the electrodes.

The anneal tends to restore symmetric values of parameters, which is coherent with a mechanism of detrapping of charges.

In conclusion, it seems that the effects on the coercive field and on the polarization are different (degradation of $\Delta P_{\mathrm{r}}$, recovery of $V_{\mathrm{c}}$ ). A hypothesis can be that the charges are spatially localised in different locations and differ in activation energy for thermal realease. They would be located in volume for $P_{\mathrm{r}}$, causing degradation of the ferroelectric domains, whereas for the coercive voltage $V_{\mathrm{c}}$, electric counter-bias would result from surface trapping, notably at grain walls and at the electrodes. The annealing of surface charges would restore the symmetry of the hysteresis cycles.

\subsection{Fatigue Effect Due to Cycling}

2.4.1. Association of Irradiation and Fatigue. - The role of impurties such that $\mathrm{Ti}, \mathrm{Fe}$ or $\mathrm{Mn}$, and their consequences on the trapping of charge, has been noted by Mihara [13] and Robertson [9], and can be understood as a chemical modification due to the ionic nature of the chemical bonding of these species.

But it has been shown that the PZT could be considered as a semiconductor of large forbidden gap of $P$ type [13]. The injection of electrons coming from electrodes during the fatigue can therefore lead to the trapping of electrons on the titanium, what can be interpreted as a chemical reduction reaction $\mathrm{Ti}^{4+}+\mathrm{e}^{-} \rightarrow \mathrm{Ti}^{3+}$. This reduction is accompanied by release of $\mathrm{O}^{-}$ions, consequently creating oxygen vacancies.

Oxygen or lead vacancies are point defects (associated or isolated) coming from the process of deposition or created by anneals (notably under hydrogenated atmosphere). These defects can act as trapping centers. Layers of $\mathbf{P}$ and $\mathrm{N}$ type can coexist, the lack of oxygen (at interfaces) producing the $\mathrm{N}$ type [13] while ferroelectric grains would be $\mathrm{P}$ type. This mechanism has been invoked to model the effect of fatigue in PZT. The growth of dendrite filaments during cycling has also been observed and induces also irreversible degradations [13].

These fatigue mechanisms being mostly charge-related, it is interesting to couple irradiation and fatigue studies to correlate the two phenomena. Tests have been undertaken on some 
Table I. - Scenarıos for urradiatıon/fatıgue experıments.

\begin{tabular}{|c|c|c|c|}
\hline $\begin{array}{c}\text { Symbol } \\
\text { in Figure } 8\end{array}$ & $\begin{array}{c}\text { Fatigue before } \\
\text { irradiation }\end{array}$ & $\begin{array}{c}\text { Irradiation } \\
(\mathrm{Mrad}(\mathrm{Si}), \text { pol. })\end{array}$ & $\begin{array}{c}\text { Fatigue after } \\
\text { irradiation }\end{array}$ \\
\hline+ & No & No & Yes \\
\hline$\bullet$ & No & Yes $(100,+5 \mathrm{~V})$ & Yes \\
\hline $\boldsymbol{\nabla}$ & No & Yes $(100,0 \mathrm{~V})$ & Yes \\
\hline $\boldsymbol{\Delta}$ & Yes $\left(6 \times 10^{5}\right.$ cycles $)$ & Yes $(100,0 \mathrm{~V})$ & Yes \\
\hline
\end{tabular}

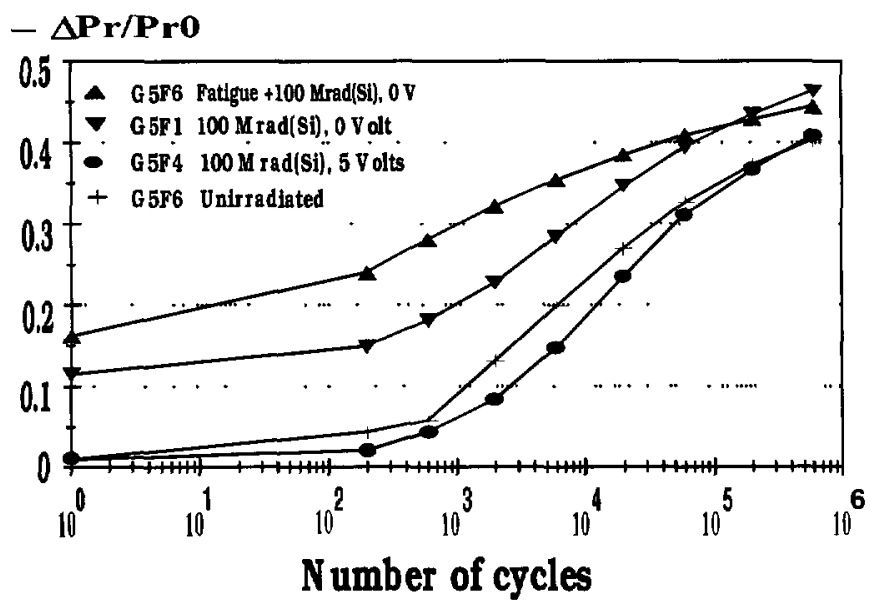

Fig $8-$ Relative variation of polarization loss $-\Delta P_{\mathrm{r}} / P_{\mathrm{r} 0}$ versus the number of cycles for four cases of irradiation/fatigue scenarios

components in the two cases: fatigue and irradiation of order to verify possible conjugated effects. The test system Radiant RT66A has been used in the fatigue mode (Annex A) with square signal $(5 \mathrm{~V},-5 \mathrm{~V})$ and a period of $5 \mathrm{~ms}$. Irradiation/fatigue scenarios are summarized in Table $\mathrm{I}$ and results Figure 8.

As one can see, the irradiation did not seem to modify the fatigue behaviour under bias (compare circles and crosses). The irradiation under zero bias favoured the post-irradiation fatigue. But, surprisingly, the fatigue before the irradiation increased strongly the post-irradiation fatigue one observed a onset of premature fatigue over one decade of cycles (compare triangles and crosses). The interpretation would necessitate to take into account the two mechanisms: fatigue and irradiation, by taking into account bulk effects such as the movement of domain walls since it is the $P_{\mathrm{r}}$ parameter that is concerned. In the absence of bias during the irradiation, charges are probably trapped at grain walls, where polarization and domain discontinuities occur.

When the fatigue cycles accumulate, the trapped charges oppose to the movement of domain walls. More and more domains are fragmented in smaller domains in the different polarization states, producing the phenomenon of pinning [14]. The net polarization is therefore decreased and the phenomenon is growing under the both stresses conditions: accumulation of radiation dose and number of fatigue cycles. 
Table II. - Irradiation/fatigue matrax. Parameters of the Weibull distributıon.

\begin{tabular}{|c|c|l|c|c|c|c|}
\hline Symb. & Fatigue & Irradiation & Fatigue & $\alpha$ & $\beta$ & $\gamma$ \\
\hline+ & No & No & Yes & 5.0 & 3.2 & 0 \\
\hline$\bullet$ & No & Yes $(+5 \mathrm{~V})$ & Yes & 5.4 & 3.6 & 0 \\
\hline $\boldsymbol{\nabla}$ & No & Yes $(0 \mathrm{~V})$ & Yes & 19.5 & 7.0 & -15 \\
\hline $\boldsymbol{\Lambda}$ & Yes & Yes $(0 \mathrm{~V})$ & Yes & 9 & $\mathbf{2}$ & -6 \\
\hline
\end{tabular}

When an external tension is applied on electrodes, charges are more likely trapped to the two interfaces with electrodes, according to their sign, the direction of the applied bias and the local polarization state of domains. Their contribution to the walls pinning is therefore less efficient, and the polarization is less affected. In summary, the fatigue test has been described as the succession of three phenomena:

1. The free domain movement, without reduction of the polarization, during the first cycles.

2. The pinning of domain walls on defects or contaminants species, especially those bearing trapped charges.

3. The fragmentation of domain: the end result is a diminution of the size of domain, and therefore of $P_{\mathrm{r}}$.

The small domains are less easy to cycle, this being due to the stronger influence of domain walls (with a larger probability for the pinning on defects). An increasing number remain in the initial polarization state.

2.4.2. Application of Weibull's Law. - We have found that a modified Weibull law could give a reasonably good representation for all scenarios of irradiation/fatigue:

$$
F(\tau)=1-\exp ^{-\frac{(\tau-\gamma)^{\beta}}{\alpha^{\beta}}}
$$

where $\tau=\log _{10}(t), \gamma$ is the failure level pre-existing to the fatigue, $\beta$ is the form factor inversely linked to the number of mechanisms in which the capacitor can degrade [15].

Table II gives the parameters matrix derived from Figure 8.

As one can see, the pre-irradiation fatigue affects strongly the parameters, more than the irradiation itself. The large values of $\beta$ do not correspond to a single mode dominating degradation, maximized by the irradiation without bias.

This observation indicates that the irradiation reveals underlying evolution of the material, that could have be interpreted in the framework of a movement of domain walls, as it has been made here, or as in [16], or in the sense of chemical transformations $[9,13]$. Supplementary work has to be made to clarify these hypotheses, and the applicability of the law of Weibull could provide useful tools.

\subsection{Comments on Mechanisms Induced by Irradiation, Fatigue and Temperature}

2.5.1. Semiconductor or Insulator? - The ferroelectric ceramics have large bandgaps (3 to $5 \mathrm{eV}, 3.5 \mathrm{eV}$ for PZT) and are normally considered as insulating. However, in equation (2), the large value of the spontaneous polarization tends to produce large electrical fields in regions where the material is inhomogeneous because of the variations in the chemical composition 
(electrodes), the physical organisation (surfaces of grains), or the dielectric permittivity (weaker values $\epsilon_{\mathrm{r}}$ in limits of grain [16]).

In the semiconductor description especially, the charges generated by irradiation or injected from electrodes are likely to move and to be captured distantly on trapping centres, thus increasing the efficiency of the degradation processes.

2.5.2. Electrical Characteristics of PZT Capacitors. - Conduction properties of PZT films have been recently investigated by several authors $[13,16,17]$ and found to be a source of controversy with regard to space charge or interface effects. The main difficulty in such studies is the device-dependence of the conduction mechanisms. In particular, it is recognized that MIM structures cannot be treated as simple devices with ohmic contacts, but rather as backto-back Schottky barriers $[10,18]$. This description is therefore simplified because some effects are neglected, such as the contribution of interface states, the polycrystallinity of PZT or the grain boundary effects which affect the state of polarization of the ferroelectric. But it provides a simple description to try to understand the electrical behaviour of ferroelectric capacitors Different models based on totally or partially depleted back-to-back Schottky barriers have been recently introduced by Brennan [10], and Teowee and Uhlmann [18]. In the framework of these last models, our arm was to briefly discuss about the effect of irradiation on the conduction properties of PZT films with Pt contacts

Figure 9 (left) shows $J(E)$ characteristics of a virgin and an irradiated PZT capacitor. No difference has been observed between the curves recorded under positive and negative biases, confirming the symmetrical behaviour of such MIM structures (at equilibrium) from a conduction point of view, even if, on the other hand, the CV characteristics exhibit a hysteresis due to the ferroelectric behaviour of the PZT material (Fig. 9 right). From Figure 9 (left), it appears that the conduction of the PZT requires a more complicated model than a simple bulk or interface conduction model, usually applied to other dielectrics. In fact, three regimes can be considered: a Schottky diode regime in region a (between $0 \mathrm{~V}$ to $\sim 3 \mathrm{~V}$ ), a ionization regime corresponding to conduction across the bulk (region b) and a breakdown regime (region c). The ionization regime can be assumed to be controlled by the ionization of defects and dopants: it is thus space charge limited.

In Figure 10 is represented an assumed band-bending structure of the PZT capacitor. Five elementary layers have be introduced: two electrodes with their barrier heights, two interface Schottky diodes with their rectification characteristics and the bulk neutral PZT. After irradiation, space charge regions should be modified, due to charge trapping. As a result, $J E$ characteristics are displaced (region a) due to the additional field induced by these fixed charges which also affect the ionization regime (Fig. 9 left).

2.5.3. Modelling as a Semiconductor. - The realistic modelling of $C(V)$ characteristics uses an equivalent system of diodes [13] and tends to confirm this concept. The modelling has to take into account the volume (insulator) and the surface of grains, electrodes and the charged defect vicinity (semiconductor). Compared to the situation of classical semiconductors, particularity comes from the large and non-linear permittivity $\epsilon_{\mathrm{r}}(E)$. The conclusions of the modelling are that charge are screened by the large value of $\epsilon_{\mathrm{r}}$ in the bulk of neutral domains where the electrical field is approaching the coercive value. These regions are equivalent to a neutral semiconductor zone. The internal field takes its largest values in boundary regions where $\epsilon_{\mathrm{r}}(E)$ drops because $E_{\mathrm{c}}$ exceeds the coercive value. In this case, the semiconductor is affected by a strong band curvature.

The form of $C(V)$ curves allows estimations of the space charge. Values can be found for irradiated samples of sol-gel PZT in regions of grain boundary: $5 \times 10^{20} \mathrm{~cm}^{-3}$ at the "surface" and $10^{18} \mathrm{~cm}^{-3}$ in the "volume" [13]. These values are in the order of magnitude of the charge 

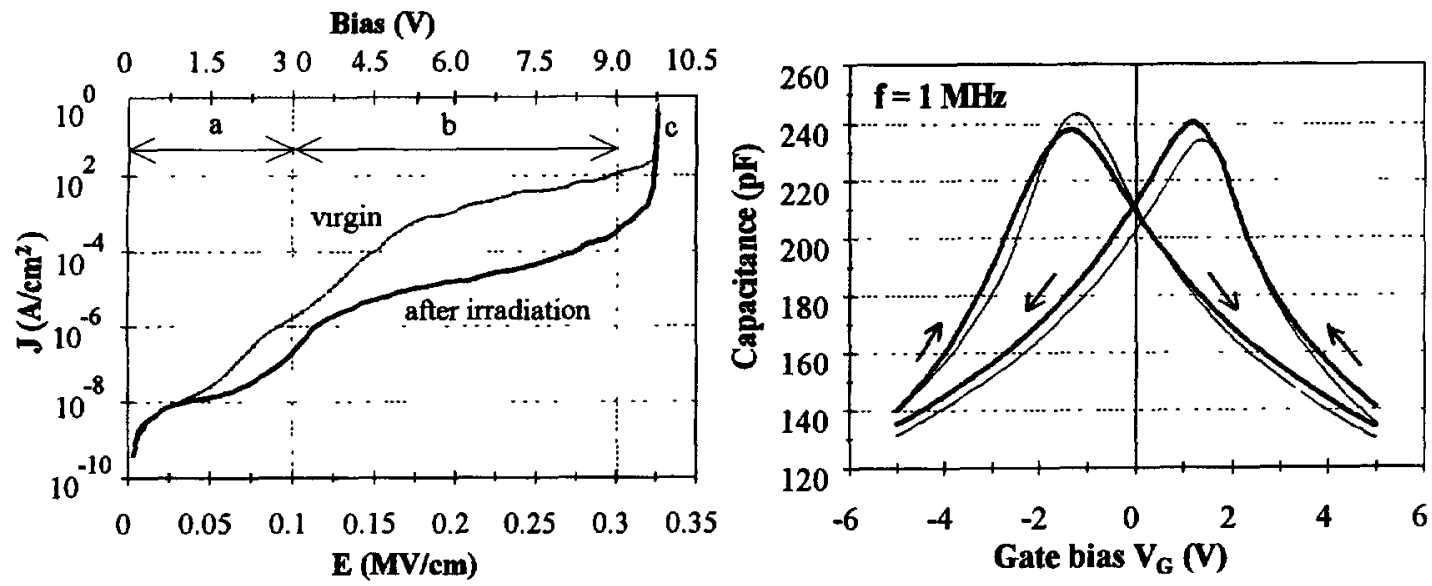

Fig. 9 - PZT film characteristics. Left $J(E)$ curves of PZT MIM capacitors before (thin line) and after (thick line) irradiation. Right Corresponding $C(V)$ curves before and after irradiation for the two sweep directions

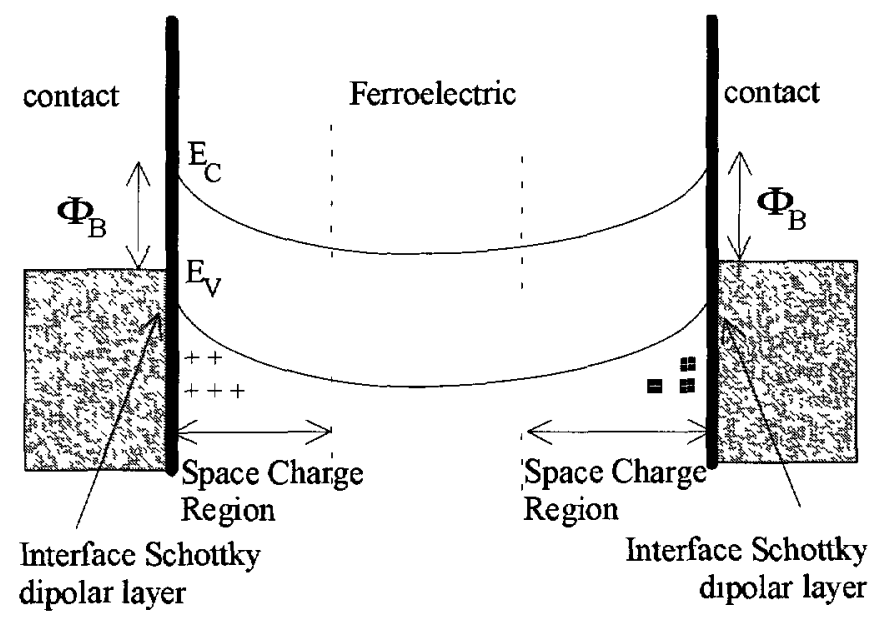

Fig. 10 - Assumed band-bending in the ferroelectric capacitor (After [10]).

density proposed to explain deformations of the cycle. Effects of radiations could have therefore resulted from the increase of the charge by trapping to surfaces of grain or in the volume of grains. The diminution of polarization would result from the variation of the width of the space charge.

The very high field reigning at the interfaces (up to $10^{8} \mathrm{~V} \mathrm{~cm}^{-1}$ on some nanometers) can induce the ionization of the point defects: intrinsic (interfaces lattice defects, vacancies, intersticials) or extrinsic (impurities), which in turn contribute to the curvature of bands, independently of the value of the gap or the depth of traps. The charges trapped on these surfaces are less screened and contribute to modify the space charge by adding their own effect on field. This ionization develops a space charge until the field at interface is screened and so that internal neutrality of the domain is re-established [16]. At this stage, the surface layer of 
the PZT material would have to be more likely described as that belonging to a semiconductor.

Practically, one can note that the diminution of $\operatorname{Pr}\left(10\right.$ to $\left.20 \mu \mathrm{C} \mathrm{cm}^{-2}\right)$ follows the estimation of the trapped charge obtained by taking into account the shift of the coercive field $\left(2.5 \times 10^{13}\right.$ to $5 \times 10^{13}$ charges $\mathrm{cm}^{-2}$ ). The two phenomena would be therefore connected.

2.5.4. Modelling as an Insulator. - Hysteresis curves after fatigue can also been understood by taking into account layers of charge trapped in planes parallel to electrodes [19]. In this case, contrarily to the model exposed in the preceding paragraph, the ferroelectric is considered as purely dielectric in its entire volume, regardless of grain and domain structure. A generalised picture could be made by superposing layers of charges so as to describe the trapping in volume as indicated in [6]. That could be true in neutral regions, where the insulator character prevails.

However, none of these models includes the ferroelectric domain movement, therefore does not give the kinetic aspect and is therefore insufficient. It could be noted also that the domain walls are, in the absence of charge trapped in volume, the only location place where the internal field and the polarization can vary because of the relationship:

$$
\operatorname{div} E_{1 \mathrm{nt}}=0 \quad \text { inside a domain }
$$

and

$$
\operatorname{div} E_{\text {int }}=\frac{\rho}{\epsilon_{0} \epsilon_{\mathrm{r}}} \text { in the domain boundary }
$$

where $\rho$ is the local density of charges (trapped charges, charged impurities, space-charge at grain interfaces, etc.).

This situation makes field to converge on these discontinuities of domain and could increase the trapping by channelling free charges towards these discontinuities. According to [13], the redistribution of charge trapped could also occur during fatigue cycling, because of movement of holes between unoccupied acceptor levels. The modelling would therefore include the description of movement of ferroelectric domain.

2.5.5. Movement and Trapping of Charges Generated by Irradiation. - The case of the insulating $\mathrm{SiO}_{2}$ used in MOS transistors is well known and can be used as a framework for reasoning. However, it is necessary to note that the dielectric constant of $\mathrm{SiO}_{2}$ is remarkably weak (3.8) and that consequently, the average field $E_{\mathrm{M}}$ and the local field $E_{\mathrm{L}}$ differ little. The situation is very different in $\mathrm{PZT}$. In $\mathrm{SiO}_{2}$, after having been generated and separated, charges are swept to electrodes due to the strong field applied on electrodes (in the order $1 \mathrm{MV} \mathrm{cm}^{-1}$ ), or trapped on defects, or recombined with trapped charge of opposite sign.

In PZT, the situation is described as deriving from a strong local field that improves the separation of pairs, but beyond, the average movement is weak because it results from a weak internal field in the volume of domains. This could favour the in situ trapping on existent defects in the volume of domains. An argument indicating that the movement of carrier is of weak amplitude has been given in [6], showing that the irradiation at $77 \mathrm{~K}$ or at the room temperature produces the same result (either biased at $+5,-5 \mathrm{~V}$ or at zero voltage). If at $77 \mathrm{~K}$, the movement of carriers is thought to be frozen (as in the case of $\mathrm{SiO}_{2}$ ), the conclusion is that this movement of carriers is also very weak to room temperature.

\subsubsection{Location of Trapped Charges}

Hypothesis of Trapping in Volume. - As a result of these considerations, some trapping centres could find their origin in the ionic behaviour of the PZT oxide and could be distributed evenly in the capacitor. The trapping in volume could have easily explain the value of the shift $\Delta E_{\mathrm{C}} \cong 1$ volt corresponding to $10^{13}$ charge $\mathrm{cm}^{-2}$, or $3 \times 10^{18}$ charges $\mathrm{cm}^{-3}$, value which is coherent with the estimated doping density derived from the modelling of the Shottky capacitor (Ref. [13], and Sect. 2.5.3). 
Table III. - Experimental data on thin film materials.

\begin{tabular}{|c|c|c|c|c|c|}
\hline Type & Origin & $\begin{array}{c}\text { Fast } \\
\text { Neutrons }\end{array}$ & Dose & Dose Rate & Reference \\
\hline & & $\mathrm{n} \mathrm{cc^{-2 }}$ & $\operatorname{rad}(\mathrm{Si})$ & $\operatorname{rad}(\mathrm{Si}) \mathrm{s}^{-1}$ & \\
\hline & & & {$[\gamma$ or X-rays $]$} & & \\
\hline $\mathrm{KNO}_{3}$ & Univ. Colorado & $\# 5 \times 10^{5}$ & $(\gamma)$ & $>2 \times 10^{11}$ & {$[20]$} \\
\hline $\mathrm{PbTiO}_{3}$ & & $>10^{14}$ & $>10^{7}(\gamma)$ & $>1.2 \times 10^{11}$ & {$[21]$} \\
\hline $\mathrm{PZT}$ & & & $10^{13} / 10^{15}$ & & {$[22]$} \\
\hline $\mathrm{PZT}$ & Krysalis & & $3 \times 10^{5}(\gamma)$ & & {$[6]$} \\
\hline $\mathrm{PZT}$ & Univ. Arizona & & $\approx 10^{6}(\gamma)$ & & {$[23]$} \\
\hline $\mathrm{PZT}$ & Univ. Colorado & & $>5 \times 10^{6}(\gamma)$ & & {$[20]$} \\
\hline $\mathrm{PZT}$ & Krysalis & & $>10^{7}(\gamma)$ & $>1.2 \times 10^{11}$ & {$[24]$} \\
\hline $\mathrm{PZT}$ & Arizona. Univ. & & $10^{7}(\mathrm{X})$ & & {$[11]$} \\
\hline $\mathrm{PZT}$ & National Semic. & & $10^{7}(\gamma)$ & & {$[6]$} \\
\hline $\mathrm{PZT}$ & National Semic. & & $>10^{7}(\gamma)$ & & {$[14]$} \\
\hline $\mathrm{PZT}$ & Sandia Nat. Lab. & & 0.5 to $2 \times 10^{7}(\gamma)$ & & {$[6]$} \\
\hline
\end{tabular}

Hypothesis of Trappıng at Surface. - On the other hand, as PZT is a polycrystalline material, a lot traps could have be situated on surfaces of monocrystalline grain. A major cause of differences in the tolerance to irradiations could come from the quality of grains and their total surface, the relevant data thus being the total grain surface by unit of surface of the capacitor. Materials of small granularity would produce therefore a large number of traps by unit of capacitor surface. This would be prejudicial to the tolerance to lonising irradiations [6].

So as to compare the data from various sources concerning the ferroelectric material, we have examined the graphs of the remanent polarization versus dose and applied a unifying criterion. The criterion for capacitors degradation in dose or neutrons exposure was $\Delta P_{\mathrm{r}} / P_{\mathrm{r}}=-20 \%$ (no bias during radiation). The criterion for dose rate was the absence of stored state corruption after a very short exposure (10 to 100 nanoseconds) [7]. Strong differences can be noted in the sensitivity to irradiations between sample of different origins and preparation methods (for instance from [6], Krysalis corporation versus and Sandia National Labs.), in connection with differences observed in TEM micrographs: 3-4 grains in the thickness for Krysalis, to be compared to one grain along the axis of thickness for Sandia.

The proportion of grain surfaces could explain differences in radiation tolerance (hardness) shown in Table III.

The Effect of Radiation Type and Energy. - In this Table, $1 \mathrm{MeV} \gamma$-rays refers to $1.25 \mathrm{MeV}$ ${ }^{60} \mathrm{Co}$, whereas X-rays refer to Aracor "10 $\mathrm{keV}$ " irradiation spectrum (see Annex B). In that case, $\operatorname{rad}(\mathrm{PZT})$ and $\operatorname{rad}(\mathrm{Si})$ notably differ, and we could find out that the conversion factor was about 4.5 ( $c f$. Annex B, Tab. V).

More refined comparison between $\mathrm{X}$-rays and $\gamma$-rays must take into account absorption profile. This is developed in the Annex B of this paper. 


\section{Conclusions}

The irradiation is a tool allowing to simulate some aspects the fatigue and to complete the study. We propose to interpretation by distinguishing:

- the role of interfaces with electrodes (semiconductor aspect, structure to analogous a Schottky diode),

- the effects in volume, dominated by stoichiometry defects $(\mathrm{O}, \mathrm{Pb})$, and metallic elements. Irreversible dendrite growths are foreseeable both as result the fatigue and the irradiation,

- the effects of domains and grain structure.

The data show the notable interest of ceramic materials ferroelectric in thin layer to stock the information, not only of non-volatile manner, what is usual and well known, but so that the information subsists in all known radiation ambience. These characteristics are a unique property of these materials.

Although the choice of samples from RADIANT is arbitrary, the comparison with bibliographical data or results from other teams shows that observations and mechanisms seem general.

However, more refined studies are conceivable, using for example measures of electronic paramagnetic resonance to determine the variation of the charge state of ions ( $\mathrm{Fe}, \mathrm{Mn}, \mathrm{Ti}$..).

\section{Acknowledgments}

It is a pleasure to thank Mrs Peccoud, MM. H. Achard, H. Massé, C. Verbeck, J.P. Ganne and P. Gaucher with whom we have had interesting discussions in 1993-1994 concerning their experimentations on the PZT capacitor.

\section{Annex A. Conditions of Measurement}

The test Radiant system RT66A [25] provides two modes to characterize ferroelectric capacities, the "Sawyer-Tawyer" mode or the "Virtual Mass" mode (a.e. integrator with operational amplifier). This latter mode is employed in this study. The period of the saw tooth for the measurement of the hysteresis cycle is $220 \mathrm{~ms}$, and the width of triangular pulses is $2 \mathrm{~ms}$ The parameter brought in this study is the remanent polarization $P_{\mathrm{r}}$. In the case of the irradiation under zero external bias (applied on electrodes), the capacity is in fact internally polarized negatively, because of the remanent polarization. Indeed, the RT66A leaves capacities in the negative state $-P_{\mathrm{r}}$ after the last measurement (the last part of the sequence of measurement consists of a negative triangle operating beyond the coercive field value). This explains that observed drifts go in general in the direction of positive applied voltages.

\section{Annex B. Conditions of Irradiation and Dosimetry}

The conditions of the irradiation and the order of magnitude of units employed are as follows:

- a tube to X-rays with tungsten anticathode fed by $60 \mathrm{kV}$, with the result that the spectrum consists of the tungsten L-lines plus bremsstrahlung background ranging from 6-7 keV to $60 \mathrm{keV}$. This spectrum is often simplified and in the case of $\mathrm{Si}$ or $\mathrm{SiO}_{2}$, is often described as equivalent to a monoenergetic line at $10 \mathrm{keV}$ [26]. 
Table IV. - Atomic numbers and atomic absorption lines of interest for materials used in $P Z T$ capacitors and memories. Also mentioned: tungsten emission lines used in $X$-ray tubes.

\begin{tabular}{|l|l|l|l|l|l|l|l|l|}
\hline Element & & $\mathrm{O}$ & $\mathrm{Si}$ & $\mathrm{Ti}$ & $\mathrm{Zr}$ & $\mathrm{W}$ & $\mathrm{Pt}$ & $\mathrm{Pb}$ \\
\hline Z number & & 8 & 14 & 22 & 40 & 74 & 78 & 82 \\
\hline K line & $(\mathrm{keV})$ & 0.533 & 1.84 & 4.970 & $\mathbf{1 8 . 0}$ & 69.52 & 78.39 & 88.0 \\
\hline L Lines & $(\mathrm{keV})$ & 0.024 & 0.15 & 0.563 & 2.53 & $\mathbf{1 2 . 1 0}$ & $\mathbf{1 3 . 8 8}$ & $\mathbf{1 5 . 9}$ \\
\hline & & 0.009 & 0.099 & 0.462 & 2.31 & $\mathbf{1 1 . 5 4}$ & $\mathbf{1 3 . 2 7}$ & $\mathbf{1 5 . 2}$ \\
\hline & & 0.009 & 0.100 & 0.456 & 2.22 & $\mathbf{1 0 . 2 1}$ & $\mathbf{1 1 . 5 6}$ & $\mathbf{1 3 . 0}$ \\
\hline
\end{tabular}

- the unit expressing the quantity of absorbed energy is the $\operatorname{rad}(\mathrm{Si})$. A megarad corresponds here to the absorption of 10 Joules by gram. This energy is partly converted in ionization. By analogy with semiconductors, one can evaluate the number of pair electron-generated holes as being in the order $10^{18} \mathrm{e}-\mathrm{h}$ pairs by $\mathrm{cm}^{3}$. The rate of the irradiation is in the order 10 megarad hour ${ }^{-1}$.

However, the $\mathrm{L}$ tungsten lines emitted by the X-ray tube are at slightly higher energy (10.21 to $12.1 \mathrm{keV}$, see Tab. IV). Therefore, Pt electrodes and PZT photoelectric absorption lines strongly absorb the X-ray spectrum. This makes the " $10 \mathrm{keV"} \mathrm{approximation} \mathrm{not} \mathrm{so} \mathrm{valid}$ as in the case of $\mathrm{Si}$, and this produces stronger dose deposition and photoelectrons emission. Photoelectrons are responsible for additional dose deposition, causing dose enhancement in light or depletion in heavy materials at interfaces. This effect is well-known and is so-called the non-equilibrium dose distribution. Up to now, these studies have been rather overlooked and that is why intercomparison of published works sometimes ambiguous.

The Phoтcoef ${ }^{\text {TM }}$ software has been used to assess and clarify dose enhancements in PZT (Tab. V). This program [27] performs calculations of photon interaction coefficient and derives equilibrium or non equilibrium total dose for monoenergetic or user-defined spectra. The dose enhancement algorithm has been described by Garth and Burke [28]. Three spectra were used: monoenergetic $1.25 \mathrm{MeV}$ representing the two 1.17 and $1.33 \mathrm{MeV}$ lines, monoenergetic $10 \mathrm{keV}$ and real spectrum as given for tube operated at $60 \mathrm{kV} \mathrm{[26].} \mathrm{The} \mathrm{dose} \mathrm{in} \mathrm{silicon} \mathrm{is} \mathrm{the} \mathrm{equilibrium}$ dose as measured in a PIN calibration or in a dosimeter $\left({ }^{60} \mathrm{Co}\right)$. The PZT capacitor is assumed to consist of an $0.3 \mu \mathrm{m} \mathrm{PbZr}_{0.2} \mathrm{Ti}_{08} \mathrm{O}_{3}$ layer sandwiched between two platinum electrodes (01 $1 \mu \mathrm{m}$ thick), on top of a $3 \mu \mathrm{m}$ silicon slab. The $\operatorname{rad}(\mathrm{PZT})$ are calculated by taking the dose enhancement into account. The $\mathrm{SiO}_{2}$ data are placed to show the consistency of the results as compared to the commonly accepted ratio for $10 \mathrm{keV}$ spectrum delivered by the tube of Aracor irradiator model 4100: this standard value is 0.56 [26].

From the dose profile examination, it can be shown that platinum electrodes play a significant and beneficial role in avoiding dose depletion from high- $\mathrm{Z}$ material (PZT) to the low-Z material ( $\mathrm{Si}$ or $\mathrm{SiO}_{2}$ ), and the PZT profile appears at equilibrium, with interface dose enhancements of only $10 \%$ with respect to the inner PZT dose. Note that the case would be completely different if different electrodes were used ( $A l, S n-A g, G a, I n, P d, P b$ cited in [29]). Photcoef also allowed to assess the dose enhancement induced in the underlying silicon layer by the sandwiched layers $\mathrm{Pt} / \mathrm{PZT} / \mathrm{Pt}$ : photoelectron flux injected from $\mathrm{Pt}$ into Si lead to enhancement factors of 2.1 for $10 \mathrm{keV}$ and 1.3 for Aracor spectra. Compared to monoenergetic $10 \mathrm{keV}$, the Aracor spectrum leads to higher dose deposition in PZT but less enhancement in silicon. This can be explained by the more complex structure of Aracor spectrum ranging from 6-7 keV to $60 \mathrm{keV}$ By referring 
Table V. - Coefficients giving the number of rad(materaal) for one rad(Si) an the Pt/PZT/Pt capacitor (Photcoef calculation).

\begin{tabular}{|c|c|c|c|}
\hline & Photon energy & $\operatorname{rad}(\mathrm{PZT}) / \mathrm{rad}(\mathrm{Si})$ & $\operatorname{rad}\left(\mathrm{SiO}_{2}\right) / \mathrm{rad}(\mathrm{Si})$ \\
\hline Monoenergetic & $1.25 \mathrm{MeV}\left({ }^{60} \mathrm{Co}\right)$ & 1.23 & 1.01 \\
\hline Monoenergetic & $10 \mathrm{keV}$ & 3.00 & 0.55 \\
\hline Tube spectrum & $\begin{array}{c}\text { L-lines + bremstrahlung } \\
\text { (at High Voltage }=60 \mathrm{kV})\end{array}$ & 4.50 & 0.55 \\
\hline
\end{tabular}

to Table $\mathrm{V}$, one can picture that Aracor spectrum interact strongly with most of the $\mathrm{L}$ line, thus reducing the photoelectrons energy and mean free paths.

These results allow to link Aracor $10 \mathrm{keV}$ irradiation and ${ }^{60} \mathrm{Co}$ deposited doses. For simplification, all the results in this paper will be nevertheless expressed in $\operatorname{rad}($ silicon); $\operatorname{rad}(\mathrm{PZT})$ will be obtained from $\operatorname{rad}(\mathrm{Si})$ by multiplication by 4.5 when obtained in Aracor $10 \mathrm{keV}$ and 1.23 when in $1.25 \mathrm{MeV}{ }^{60} \mathrm{Co}$. For comparison, it can be recalled that $\operatorname{rad}\left(\mathrm{SiO}_{2}\right)$ are obtained by multiplying by 0.55 and 1 . But care should be taken in low energy X-ray irradiation. Dose expression $\mathrm{rad}(\mathrm{Si})$ as well as röntgen without mentioning the spectrum could lead to heavy misunderstandings.

\section{References}

[1] Leray J L., Paillet P. and Autran J.L., An overview of buried oxides on silicon. new processes and radiation effects, J. Phys. III France 6 (1996) 1625-1646.

[2] Fatuzzo E. and Mertz W.J., Ferroelectricity (Amsterdam: North Holland Publishing Company, 1967) p. 252.

[3] Wittels M.C. and Sherill F A, Fast Neutron Effects in Tetragonal Barium Titanate, J. Appl. Phys. 28 (1957) 606.

[4] Lefkovwitz I. and Mitsui T., Effect of $\gamma$-Ray and Pile Irradiation on the Coercive Field of $\mathrm{BaTiO}_{3}$, J. Appl. Phys 30 (1959) 269.

[5] Chynoweth A.G., Radiation Damage Effects in Ferroelectric Triglycine Sulfate, Phys. Rev. 113 (1959) 159.

[6] Schwank J.R., Nasby R.D., Miller S.L., Rodgers M.S. and Dressendorfer P.V., Total-Dose Radiation-Induced Degradation of Thin Film Ferroelectric Capacitors, IEEE Trans. Nucl. Scr. 37 (Dec 1990) 1703.

[7] Coïc Y.M., Musseau O. and Leray J.L., A study of Radiation Vulnerability of Ferroelectric Material and Devices, IEEE Trans. On Nuclear Scrence 41 (June 1994) 495.

[8] Verbeck C. and Gaucher P., Nuclear Evaluation of PZT Thin Films for Non-Volatile Memories, Proc of the RADECS International Conference, IEEE catalog Number 93TH0616-3 (Sept. 1993, Saint-Malo, France).

[9] Robertson J., Warren W.L., Turtle B.A., Dimos D. and Smyth D.M., Shallow $\mathrm{Pb}^{3+}$ Hole Traps in Lead Zirconate Titanate Ferroelectric, Appl. Phys. Lett. 63 (1993) 1519.

[10] Brennan C.J., Characterization and Modelling of Thin-Film Ferroelectric Capacitors using C-V Analysis, in Proc. of the 3rd International Symposium on Integrated Ferroelectrics (ISIF-91), C. Paz de Araujo, Ed. (Univ. of Colorado at Colorado Sprıngs, USA) pp. 354363. 
[11] Benedetto J.M., Moore R.A., McLean F B., Brody P.S. and Dey S.K., The Effect Of Ionizing Radiation on Sol-Gel Ferroelectric PZT Capacitor, IEEE Trans. Nucl. Scr. 37 (Dec. 1990) 1713.

[12] Duiker H.M., Beale P.D., Schott J.F., Paz de Araujo C.A., Melnick B.M., Cuchiaro J.D. and McMillan L.D., Fatigue and Switching in Ferroelectric Memories: Theory and Experiment, J. App. Phys. 68 (Dec. 1990).

[13] Mihara T., Watanabe H., Yoshimori H., Paz De Araujo C.A., Melnick B. and McMillan L.D., Process Dependent Electrical Characteristics and Equivalent Circuit Model of Sol-Gel Based PZT Capacitors, Proc. of the 3rd International Symposium on Integrated Ferroelectrics (ISIF-91), C. Paz de Araujo, Ed. (Univ. of Colorado at Colorado Springs, USA) pp. 116-138.

[14] Benedetto J.M., DeLancey W.M., Oldham T.R., McGarrity J.M. and Tipton C.W., Radiation Evaluation of Commercial Ferroelectric Nonvolatile Memories, IEEE Trans. Nucl. Sci. 38 (Dec. 1991) 1713.

[15] Ross R., Bias and Standard Deviation due to Weibull Parameter Estimation for Small Data Sheet, IEEE Trans. On Dielectric Insulation 3 (Feb. 1996) 28-42.

[16] Scott J.F., Melnıck B.M , Paz de Araujo C.A., McMillan L.D. and Zuleeg R., D.C leakage currents in ferroelectric memories, Proc. 2nd Int. Symp. Integrated Ferroelectrics, C.A. de Araujo, Ed. (Colorado Spring, 1991) 176-184. See also references inside.

[17] Scott J.F., Ferroelectric thin films and thin film devices, Ferroelectric ceramics, N. Setter and E.L. Colla, Eds. (Basel: Birkhäuser Verlag, 1993) pp. 185-212.

[18] Teowee G. and Uhlmann D.R., A model of the metal-ferroelectric-metal capacitor, Mat. Res. Soc. Symp. 310 (1993) 415-422.

[19] Miller S.L., Schwank J.R., Nasby R.D. and Rodger M.S., Modeling Ferroelectric Capacitor Switching with Asymmetric Nonperiodic Input Signals and Arbitrary Initıal Conditions, J. Appl. Phys. 70 (1991) 2849.

[20] Scott J.F., Paz de Araujo C.A., Meadows H.B., McMillan L.D. and Shawabkeh A., Radiation Effects On Ferroelectric Thin-Film Memories: Retention Failure Mechanisms, $J$. Appl. Phys. 66 (1989) 1444.

[21] Messenger G.C. and Coppage F.N., Ferroelectric Memories: A Possible Answer to the Hardened Nonvolatile Question, IEEE Trans. Nucl. Sci. 35 (Dec. 1988) 1461.

[22] Moore R.A., Benedetto J.M., McGarrity J.M. and McLean F.B., Neutron Radiation Effects on PZT Thin Films for Nonvolatile-Memory Applications, IEEE Trans. Nucl. Scr. 38 (Dec. 1991) 1078.

[23] Lee S.C., Teowee G., Schrimpf R.D., Birnie D.P., Uhlmann D.R. and Galloway K.F., Total Dose Radiation Effects on Sol-Gel Derived PZT Thin Films, IEEE Trans. Nucl. Sci. 39 (Dec. 1992) 2036.

[24] Wrobel T.F., Bullington J.A. and Schwee L.J., Radiation Hardness of Thin Ferroelectric Capacitors, In Gomac Digest of Papers (1987) p. 267.

[25] "RT66A Standardized Ferroelectric Tester V2.1 Operating Manual", RADIANT Technologies, 1009 Bradbury Drive SE, Albuquerque NM87106, USA.

[26] Palkuti L.J. and LePage J.J., X-ray Wafer Probe for Total Dose Testing, IEEE Trans. Nucl. Sci. 29 (Dec. 1982) 1832.

[27] AIC Software, P.O. Box 544, Grafton, MA 01519, USA (Fax: 508-839-6779).

[28] Garth J.C., An Algorithm for Calculating Dose Profiles in Multi-Layered Devices using a Personal Computer, IEEE Trans. Nucl. Sci. 33 (Dec. 1986) 1266.

[29] Dressendorfer P., An Overview of Advanced Nonvolatile Memory Technologies, IEEE NSRE Conf. Short Course (San Diego, USA, 1991). 